\title{
Association of plasma triglyceride and C-peptide with coronary heart disease in Japanese-American men with a high prevalence of glucose intolerance
}

\author{
R.W.Bergstrom ${ }^{1}$, D. L. Leonetti ${ }^{2}$, L.L. Newell-Morris ${ }^{2}$, W.P. Shuman ${ }^{3}$, P.W. Wahl ${ }^{4}$ and W. Y.Fujimoto ${ }^{1}$ \\ Departments of ${ }^{1}$ Medicine, ${ }^{2}$ Anthropology, ${ }^{3}$ Radiology, and ${ }^{4}$ Biostatistics, University of Washington, Seattle, Washington, USA
}

\begin{abstract}
Summary. In a community-based study of second-generation Japanese-American men known to have a high prevalence of both Type 2 (non-insulin-dependent) diabetes and impaired glucose tolerance, there was a highly significant association of coronary heart disease with glucose intolerance in a study sample of 219 men. Intra-abdominal cross sectional fat area determined by computed tomography was significantly elevated in men with coronary heart disease even after adjustment for glucose intolerance and body mass index $(p=0.026)$. Other differences that were significantly related to coronary heart disease after adjustment for glucose intolerance were lower high density lipoprotein cholesterol levels $(p=0.001)$, elevated total triglyceride and very low density lipoprotein triglyceride $(p<0.001)$, and
\end{abstract}

elevated fasting insulin and C-peptide levels $p=0.001$. When these variables were tested in a stepwise multiple logistic regression model, significant independent associations with coronary heart disease were found only for total triglyceride and fasting C-peptide after adjustment for glucose tolerance status. Variables identified to be associated with coronary heart disease were interpreted as representing or manifesting an insulin resistant state. Thus, insulin resistance may be the underlying risk factor aetiologically linking glucose intolerance with coronary heart disease.

Key words: Coronary heart disease, glucose intolerance, triglyceride, C-peptide, intra-abdominal fat area, Type 2 (non-insulin-dependent) diabetes.
The association between glucose intolerance, both impaired glucose tolerance and Type 2 (non-insulin-dependent) diabetes and coronary heart disease has been attributed to multiple factors and their interactions [1, 2]. The precise roles of many of these factors in the pathogenesis of coronary heart disease is still not completely understood. One factor that is associated with glucose intolerance and has been implicated as being relevant to coronary heart disease from epidemiological studies [3-6] and experimental studies [7] is hyperinsulinaemia. This relationship is thought to be mediated by insulin resistance [8]. Both fasting insulin and fasting C-peptide have been employed as a measure of insulin resistance [8-11]. However C-peptide is not metabolized by the liver and is therefore a more reliable index of prehepatic insulin secretion than the fasting insulin [12]. High C-peptide levels have been interpreted as representing hypersecretion of insulin as a compensatory response to insulin resistance $[8,11]$. Elevated C-peptide levels have been shown to precede the development of Type 2 diabetes in Japanese American men [11]. Insulin resistance is increased in obesity and with site-specific differences in body fat deposits, which are also characteristically associated with
Type 2 diabetes and coronary heart disease $[13,14]$. Potentially atherogenic lipoprotein abnormalities are also frequently observed in Type 2 diabetes [1, 2, 13-17]. Moreover, in populations with glucose intolerance, elevated triglyceride levels have been associated with the subsequent progression to Type 2 diabetes [18] and coronary heart disease mortality [19].

In several epidemiological studies, the rates of both coronary heart disease and glucose intolerance have been found to be higher among Japanese-Americans than in comparison populations of native Japanese $[20,21]$. The purpose of the cross-sectional study described here was to identify in a Japanese-American population known to have a high prevalence of both impaired glucose tolerance and Type 2 diabetes factors that may account for this association of glucose intolerance with coronary heart disease.

\section{Subjects and methods}

The Japanese-American Community Diabetes Study is an epidemiological study to evaluate factors associated with Type 2 diabetes and its attendant complications among Japanese-Americans 


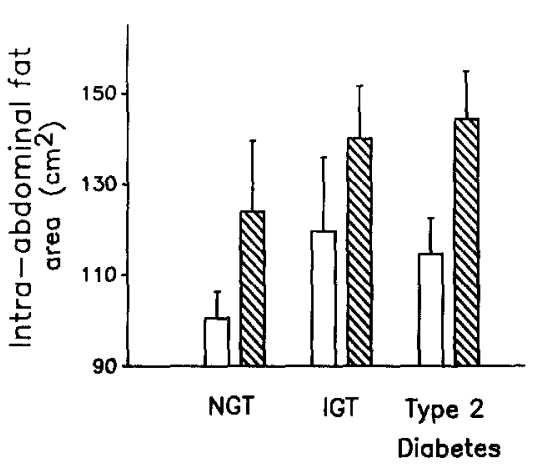

Fig. 1. Intra-abdominal cross-sectional fat area related to the presence $\mathbb{\$}$ and absence $\square$ of coronary heart disease, by glucose tolerance diagnosis (NGT, normal glucose tolerance; IGT, impaired glucose tolerance). Analysis of variance: Main effects, $p<0.001$; coronary heart disease, $p=0.004$; glucose tolerance; $p=0.09$; interaction, $p=0.89$. Values are mean \pm SEM

living in King County, Washington. From this population, 229 Japanese-American Nisei men (American born and reared sons of immigrants from Japan) were enrolled into the study. Details pertaining to the recruitment, enrollment, characterization and generational assignment of the study group have been reported previously [11, 22, 23]. Briefly, the 229 men in the study group were selected from 487 volunteers. Men with self-reported diabetes $(n=117)$ were first screened for enrollment and 76 were accepted. The reasons for exclusion have been given previously [22]. The remaining 370 self-reported non-diabetic volunteer men were randomly chosen and screened for eligibility until the age distribution of the men with a final diagnosis of diabetes was matched, resulting in an enrollment of 153 self-reported non-diabetic men. The almost equal distribution of normal, impaired glucose tolerant, and diabetic men in the final diagnostic classification of subjects was a consequence of this selection design. To establish that the study group was representative of King County Nisei men, it was compared and found to be similar with regard to several demographic characteristics to a reference group that was derived by a random sample of the study population of Nisei men in King County.

Each of the subjects was studied at the Clinical Research Center, University of Washington Medical Center. Glucose tolerance status was classified as normal, impaired and Type 2 diabetes based upon medical information obtained from the subjects and their physicians and the results of a $75 \mathrm{~g}$ oral glucose tolerance test [22]. Based upon this information, 77 of the study group had normal glucose tolerance, 74 had impaired glucose tolerance and $78 \mathrm{had}$ Type 2 diabetes. The prevalence rates of diabetes and impaired glucose tolerance in the study population have been estimated to be $20 \%$ and $36 \%$, respectively [22]. The proportion of diabetic subjects in the study group is higher $(34 \%)$, reflecting the research design. Ten subjects with Type 2 diabetes were receiving insulin therapy and were excluded from the present analysis, resulting in a study sample of 219 men. Of the remaining 68 diabetic men, 28 were receiving oral hypoglycaemic agents. The protocol for this research was reviewed and approved by the Human Subjects Review Committee at the University of Washington. Written informed consent was obtained from each subject.

\section{Variables}

Age (years and months) was converted to proportions of a year. History of cigarette smoking (expressed as years smoked), physical activity, and alcohol intake were estimated by questionnaire. Physical activity level (usual kilocalories expended weekly) was estimated from the following: "strenuous" exercise $=10 \mathrm{kcal} /$ - min; sports activities adjusted for seasonal variation at $5 \mathrm{kcal} / \mathrm{min}$ for "light" sports, $10 \mathrm{kcal} / \mathrm{min}$ for "strenuous" sports, and $7.5 \mathrm{kcal} / \mathrm{min}$ for combinations of these; one flight of stairs climbed per day $=28 \mathrm{kcal} /$ week; and one block walked per day = $56 \mathrm{kcal} /$ week (24). Alcohol intake was estimated as low ( $<3 \mathrm{~g} /$ day), moderate (3-29 g/day), or heavy ( $\geq 30 \mathrm{~g} /$ day). Height $(\mathrm{m})$ and weight $(\mathrm{kg})$ were measured, and the body mass index was calculated as $\mathrm{kg} / \mathrm{m}^{2}$.

Blood pressure was the mean of three consecutive measurements with a mercury sphygmomanometer, with the subject recumbent. The systolic blood pressure was determined at the first perception of sound and the diastolic blood pressure was recorded at the disappearance of Korotkoff sound (Phase 5). Hypertension was defined by either diastolic blood pressure $>90 \mathrm{~mm} \mathrm{Hg}$ or systolic blood pressure $>140 \mathrm{~mm} \mathrm{Hg}$. The presence of coronary heart disease was determined from the medical history (angina, myocardial infarction, coronary artery bypass graft, or coronary angioplasty), responses to the London School of Hygiene Cardiovascular Questionnaire indicating angina or possible infarction [25], and Minnesota Code criteria for a resting 12-lead electrocardiogram (items 1.1-1.3 \{abnormal $Q$ and $Q S$ patterns], 5.1-5.3 \{abnormalities of T-waves\} or 7.1 (left bundle branch block\}) [26]. Fifty-four of the 219 Nisei men had coronary heart disease by these criteria.

Cross-sectional body fat areas $\left(\mathrm{cm}^{2}\right)$ were determined by computed tomography at four sites (subcutaneous thorax, subcutaneous abdomen, subcutaneous thigh and intra-abdominal) as previously reported $[11,27]$. Intraobserver variability ranged from $0.2 \%$ of the mean for the thigh to $1.4 \%$ of the mean for the thorax [27]. Skinfold thickness ( $\mathrm{mm}$ ) was measured (Lange calipers) on the left side of the body at four different anatomic sites (triceps, biceps, forearm and subscapular).

Blood samples were drawn after a $10 \mathrm{~h}$ fast for measurement of serum glucose and plasma lipids, lipoproteins, insulin and $\mathrm{C}$ peptide and blood samples were then drawn at 30,60, 90, 120 and $180 \mathrm{~min}$ following $75 \mathrm{~g}$ oral glucose to measure serum glucose and plasma insulin and C-peptide levels. The fasting insulin/glucose or C-peptide/glucose was the quotient of these plasma peptides divided by the simultaneous serum glucose. All the lipid and lipoprotein measurements were performed at the Northwest Lipid Research Laboratory, according to modified procedures of the Lipid Research Clinics [28]. Apoprotein $\mathrm{A}_{1}$ and apoprotein $\mathrm{B}$ were determined by standardized radioimmunoassays. The serum glucose was measured by an automated glucose oxidase method (University of Washington Medical Center, Department of Laboratory Medicine). Both plasma insulin and $\mathrm{C}$-peptide were measured by radioimmunoassays performed in the Radioimmunoassay Core of the Diabetes Endocrinology Research Center. The intraassay and inter-assay coefficient of variation were $5 \%$ and $8 \%$ for insulin and $7 \%$ and $11 \%$ for C-peptide.

Table 1. Adiposity and site-specific fat measurements

\begin{tabular}{lrrr}
\hline & \multicolumn{2}{c}{ Coronary heart disease } & $p$-value \\
\cline { 2 - 3 } & \multicolumn{1}{c}{$\begin{array}{l}\text { Present } \\
(54)\end{array}$} & $\begin{array}{l}\text { Absent } \\
(165)\end{array}$ & \\
\hline Body mass index $\left(\mathrm{kg} / \mathrm{m}^{2}\right)$ & $26.3 \pm 0.4$ & $25.3 \pm 0.2$ & 0.013 \\
Skinfold thickness $(\mathrm{mm})$ & & & \\
Forearm & $6.3 \pm 0.3$ & $5.6 \pm 0.2$ & 0.03 \\
Biceps & $8.2 \pm 0.5$ & $6.8 \pm 0.2$ & 0.024 \\
Subscapular & $21.2 \pm 0.9$ & $18.2 \pm 0.5$ & $<0.001$ \\
Triceps & $8.7 \pm 0.4$ & $8.5 \pm 0.2$ & 0.61 \\
Computed tomography fat areas $\left(\mathrm{cm}^{2}\right)$ & & \\
Subcutaneous thorax & $109.4 \pm 5.6$ & $92.8 \pm 3.4$ & 0.006 \\
Subcutaneous abdomen & $151.8 \pm 7.8$ & $131.8 \pm 4.9$ & 0.018 \\
Subcutaneous thigh & $43.2 \pm 1.9$ & $42.0 \pm 1.3$ & 0.68 \\
Intra-abdominal & $140.1 \pm 7.3$ & $109.7 \pm 4.1$ & $<0.001$ \\
\hline
\end{tabular}

Values are mean \pm SEM 


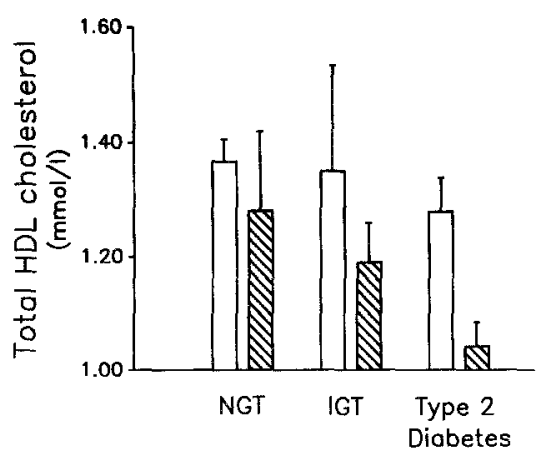

Fig. 2. Total HDL cholesterol related to the presence or absence $\square$ of coronary heart disease, by glucose tolerance diagnosis (NGT, normal glucose tolerance; IGT, impaired glucose tolerance). Analysis of variance: Main effects, $p<0.001$; coronary heart disease, $p=0.001$; glucose tolerance; $p=0.049$; interaction, $p=0.57$. Values are mean \pm SEM

\section{Statistical analysis}

The variables with highly skewed distributions (total and VLDL triglyceride, $\mathrm{HDL}$ and $\mathrm{HDL}_{2}$ cholesterol, and fasting C-peptide and insulin levels) were transformed logarithmically. A square root transformation was used on the physical activity variable. Differences between the groups were analysed by applying the nonparametric Wilcoxon Rank Sum Test or the Chi Square Test as appropriate. Risk factors were analysed using two-way analysis of variance with coronary heart disease (absence or presence) and glucose tolerance status (normal or impaired glucose tolerance, or diabetes) as the grouping variables. Spearman Rank correlation coefficients were calculated for pairs of continuous variables. A stepwise method of multiple logistic regression analysis was performed to determine which variables were related to coronary heart disease after controlling for glucose intolerance and medications which could alter either glucose tolerance or lipid values. All the values are expressed as mean \pm SEM.

\section{Results}

\section{Clinical characteristics}

The presence of known risk factors for coronary heart disease were compared between men with and without heart disease. Mean age (years) was not significantly different ( $62.0 \pm 0.8$ vs $61.3 \pm 0.5, p=0.63)$; age ranges were $50-74$ years and $45-73$ years. A greater proportion of men with coronary heart disease were hypertensive but this difference was only marginally significant $(64.8 \%$ vs $50.9 \%, p=0.08)$. However, there were significantly higher mean levels of both systolic and diastolic blood pressure $(\mathrm{mm} \mathrm{Hg})$ in men with compared to those without coronary heart disease: systolic $144.7 \pm 2.7$ vs $137.2 \pm 1.3(p=0.008)$, diastolic $83.8 \pm 1.2$ vs $79.9 \pm 0.7$ $(p=0.007)$. Greater use of cigarettes (years smoked) was significantly associated with coronary heart disease $(25.2 \pm 2.2$ vs $19.6 \pm 1.1, p=0.019)$. The difference in physical activity between men with coronary heart disease and those without was not significant $(2155 \pm 39$ vs $2339 \pm 26 \mathrm{kcal} / \mathrm{week}$ ). Those persons with moderate alcohol intake had less coronary heart disease $(15.3 \%)$ than those with low $(27.9 \%)$ or high intake $\left(38.9 \% ; \chi^{2}=6.11\right.$,

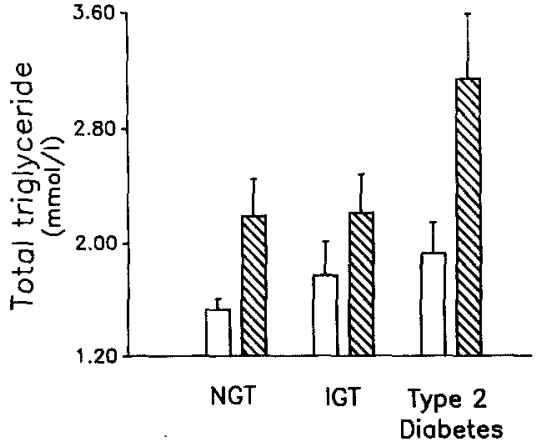

Fig. 3. Total triglyceride related to the presence $\$$ and absence $\square$ of coronary heart disease, by glucose tolerance diagnosis (NGT, normal glucose tolerance; IGT, impaired glucose tolerance). Analysis of variance: Main effects, $p<0.001$; coronary heart disease, $p<0.001$; glucose tolerance, $p=0.125$; interaction, $p=0.581$. Values are mean \pm SEM

$p=0.047$ ). The percentage of men with coronary heart disease progressively increased with each of the glucose tolerance categories (normal $-9.1 \%\{n=7\}$, impaired $27.0 \%\{n=20\}$, and diabetes $-39.7 \%\{n=27\} ; \chi^{2}=18.56$, $p<0.001)$ and was observed when comparing the normal and impaired glucose tolerance groups $\left(\chi^{2}=8.27\right.$, $p=0.004)$. and the normal glucose tolerance and diabetes groups $\left(\chi^{2}=18.86, p<0.001\right)$. The presence of coronary heart disease was not significantly different between the impaired glucose tolerance and diabetes groups $\left(\chi^{2}=2.57, p=0.11\right)$.

\section{Adiposity and site-specific fat measurements}

Body mass index and three skinfold thickness measurements, biceps, forearm, and subscapular, were significantly elevated in those men with coronary heart disease (Table 1). Similarly, the computed tomography determined cross-sectional intra-abdominal, subcutaneous abdominal and subcutaneous thoracic fat areas were significantly increased in those men with heart disease. After an adjustment for glucose tolerance status (using it as a grouping variable along with coronary heart disease in a two-way analysis of variance) for each of these nine variables, only the intra-abdominal fat area was significantly associated with heart disease (Fig. 1). The association of the intra-abdominal fat area with coronary heart disease remained significant after adjusting for body mass index as a covariate.

\section{Lipids and lipoproteins}

Total cholesterol was not different between men with and without coronary heart disease (Table 2). However, cholesterol derived from both LDL and HDL was significantly lower in men with heart disease. Further subdivision of $\mathrm{HDL}$ cholesterol into $\mathrm{HDL}_{2}$ and $\mathrm{HDL}_{3}$ cholesterol revealed both to be lower in men with heart disease. Conversely, total triglyceride and VLDL triglyceride were higher in men with heart disease. The cholesterol from 


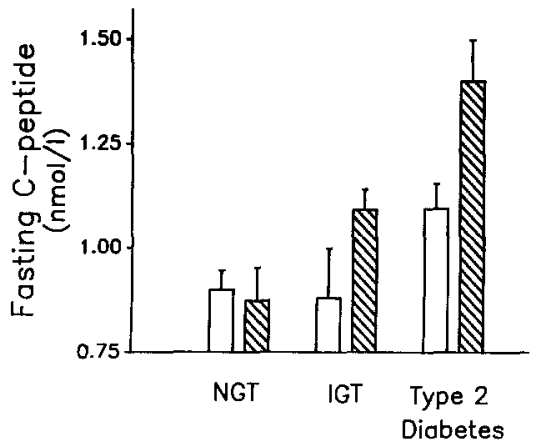

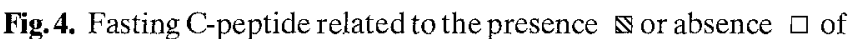
coronary heart disease, by glucose tolerance diagnosis (NGT, normal glucose tolerance; IGT, impaired glucose tolerance). Analysis of variance: Main effects, $p<0.001$; coronary heart disease, $p=0.001$; glucose tolerance, $p<0.001$; interaction, $p=0.168$. Values are mean \pm SEM

VLDL was also higher in men with heart disease. Apoprotein $\mathrm{A}_{1}$ was significantly lower in the men with heart disease while apoprotein $B$ was not significantly different. The lower HDL cholesterol and higher total triglyceride remained significant after adjustment for glucose tolerance status (Figs. 2 and 3). By similar analysis, both lower $\mathrm{HDL}_{2}$ cholesterol and elevated VLDL triglyceride were also significant for coronary heart disease $(p=0.02$, $p<0.001$; respectively).

\section{Insulin and C-peptide}

Fasting C-peptide and insulin levels were both significantly elevated in men with CHD vs those without CHD $(1.22 \pm 0.07 \mathrm{nmol} / \mathrm{l}$ vs $0.93 \pm 0.03 \mathrm{nmol} / \mathrm{l}, p<0.001$; and $116 \pm 11 \mathrm{pmol} / 1$ vs $84 \pm 4 \mathrm{pmol} / 1, p=0.006$; respectively). Since the fasting C-peptide and insulin levels may be in part determine by the simultaneous glucose levels, both were adjusted for the fasting glucose. The fasting C-peptide/glucose and insulin/glucose were still significantly elevated in those men with coronary heart disease $(18.3 \pm 0.8 \mathrm{nmol} / \mathrm{mmol}$ vs $14.9 \pm 0.5 \mathrm{nmol} / \mathrm{mmol}, p<0.001$; and $1.68 \pm 0.13 \mathrm{nmol} / \mathrm{mmol}$ vs $1.31 \pm 0.04 \mathrm{nmol} / \mathrm{mmol}$, $p=0.009 ;$ respectively). Although glucose intolerance was more strongly associated with hyperinsulinaemia than was coronary heart disease, the elevation of both fasting insulin and C-peptide with heart disease remained significant after the glucose intolerance status was introduced as a grouping variable along with heart disease in the analysis (Figs. 4 and 5).

\section{Multivariate analysis}

For the entire study sample of 219 Nisei men, both the fasting insulin and C-peptide levels were positively correlated with body mass index, intra-abdominal fat, total triglyceride and VLDL triglyceride, and inversely correlated with $\mathrm{HDL}$ and $\mathrm{HDL}_{2}$ cholesterol levels (Table 3 ). There was a weaker but still significant positive correla-

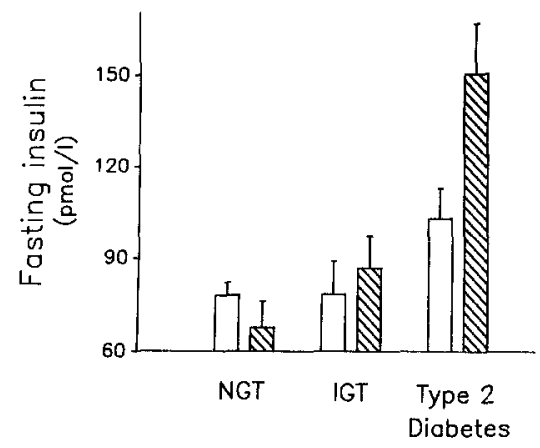

Fig.5. Fasting insulin related to the presence $\mathbb{\otimes}$ or absence $\square$ of coronary heart disease, by glucose tolerance diagnosis (NGT, normal glucose tolerance; IGT, impaired glucose tolerance). Analysis of variance: Main effects, $p<0.001$; coronary heart disease, $p=0.03$; glucose tolerance, $p<0.001$; interaction, $p=0.06$. Values are mean $\pm \mathrm{SEM}$

tion of both fasting insulin and C-peptide levels with both systolic and diastolic blood pressure levels. The total triglyceride was positively correlated with body mass index, intra-abdominal fat, and VLDL triglyceride and inversely correlated with $\mathrm{HDL}$ and $\mathrm{HDL}_{2}$ cholesterol. Total triglyceride had a weaker but significant positive correlation with diastolic blood pressure. There was no significant correlation between total triglyceride and systolic blood pressure level.

Because of these interrelationships, a stepwise multiple logistic regression model was used to assess the contribution of many of these variables to coronary heart disease. This model included both known and proposed risk factors for heart disease: age, cigarette use, physical activity, alcohol intake, hypertension, obesity, and intra-abdominal fat area, and plasma levels of LDL and HDL cholesterol, total triglyceride, fasting insulin, and fasting C-peptide. In addition, treatment with either beta adrenergic antagonists or diuretics was tested by Chi square analysis for a relationship to heart disease because these agents are known to alter lipid and glucose parameters. Diuretic therapy was not associated with coronary heart disease while therapy with beta adrenergic antagonists was associated with heart disease $\left(\chi^{2}=6.58, p=0.037\right)$. This latter variable was forced in-

Table 2. Plasma lipid and lipoprotein levels ( $\mathrm{mmol} / \mathrm{l})$

\begin{tabular}{lccc}
\hline & \multicolumn{2}{l}{ Coronary heart disease } & \multirow{2}{*}{$p$-value } \\
\cline { 2 - 3 } & $\begin{array}{l}\text { Present } \\
(54)\end{array}$ & $\begin{array}{l}\text { Absent } \\
(165)\end{array}$ & \\
\hline Total cholesterol & $5.96 \pm 0.16$ & $6.12 \pm 0.08$ & 0.28 \\
VLDL cholesterol & $1.26 \pm 0.13$ & $0.80 \pm 0.04$ & $<0.001$ \\
LDL cholesterol & $3.56 \pm 0.15$ & $3.98 \pm 0.03$ & 0.014 \\
HDL cholesterol & $1.13 \pm 0.04$ & $1.34 \pm 0.03$ & $<0.001$ \\
HDL $_{2}$ cholesterol & $0.18 \pm 0.02$ & $0.29 \pm 0.02$ & $<0.001$ \\
HDL $_{3}$ cholesterol & $0.95 \pm 0.02$ & $1.05 \pm 0.01$ & $<0.001$ \\
Total triglyceride & $2.68 \pm 0.26$ & $1.71 \pm 0.08$ & $<0.001$ \\
VLDL triglyceride & $2.10 \pm 0.23$ & $1.20 \pm 0.07$ & $<0.001$ \\
Apoprotein $\mathrm{A}_{1}(\mathrm{mg} / \mathrm{dl})$ & $136.4 \pm 2.6$ & $147.0 \pm 1.9$ & 0.004 \\
Apoprotein $\mathrm{B}(\mathrm{mg} / \mathrm{dl})$ & $126.3 \pm 3.8$ & $128.8 \pm 2.3$ & 0.62 \\
\hline
\end{tabular}

Values are mean \pm SEM 
Table 3. Correlation coefficients of C-peptide, insulin, and triglyceride levels with selected variables

\begin{tabular}{lrcc}
\hline & Fasting & & $\begin{array}{c}\text { Total tri- } \\
\text { glyceride }\end{array}$ \\
\cline { 2 - 3 } & Insulin & C-peptide & \\
\hline Body mass index & 0.503 & 0.253 & 0.345 \\
Intra-abdominal fat & 0.512 & 0.282 & 0.383 \\
HDL cholesterol & -0.441 & -0.292 & -0.686 \\
HDL 2 cholesterol & -0.431 & -0.279 & -0.701 \\
VLDL triglyceride & 0.450 & 0.301 & 0.975 \\
Total triglyceride & 0.418 & 0.312 & 1.000 \\
\hline
\end{tabular}

All of the correlation coefficients were significant, $p<0.01$

Table 4. Final equation of stepwise multiple logistic regression analysis of coronary heart disease with forced entry of glucose tolerance status (impaired glucose tolerance and Type 2 (non-insulin-dependent) diabetes), beta adrenergic antagonist therapy, and oral hypoglycaemic medication therapy

\begin{tabular}{lrrrl}
\hline Variable & $\begin{array}{l}\text { Coeffi- } \\
\text { cient }\end{array}$ & $\begin{array}{l}\text { Stan- } \\
\text { dard } \\
\text { error }\end{array}$ & $\begin{array}{l}\text { Stand- } \\
\text { ardized } \\
\text { coefficient }\end{array}$ & $p$ value \\
\hline $\begin{array}{l}\text { Impaired glucose } \\
\text { tolerance }\end{array}$ & 0.555 & 0.255 & 2.175 & 0.024 \\
$\begin{array}{l}\text { Type 2 diabetes } \\
\text { Beta adrenergic }\end{array}$ & 0.756 & 0.284 & 2.664 & 0.0063 \\
antagonist therapy & 0.182 & 0.216 & 0.842 & 0.40 \\
$\begin{array}{l}\text { Oral hypoglycaemic } \\
\text { therapy }\end{array}$ & -0.449 & 0.300 & -1.499 & 0.13 \\
Years smoked & 0.025 & 0.012 & 2.019 & 0.040 \\
Moderate alcohol & -0.480 & 0.223 & -2.159 & 0.025 \\
$\begin{array}{l}\text { Heavy alcohol } \\
\text { Total triglyceride }\end{array}$ & 0.141 & 0.324 & 0.435 & 0.67 \\
Fasting C-peptide & 0.911 & 0.372 & 2.449 & 0.012 \\
\hline
\end{tabular}

to the model to control for the effects of beta adrenergic antagonist therapy. Finally, the model was also controlled for glucose tolerance status (both diabetes and impaired glucose tolerance) and oral hypoglycaemic medication in order to assess their relationships with coronary heart disease in multivariate analysis. The forced entry into the model was performed since subjects with Type 2 diabetes were preferentially enrolled into the study sample. The analysis showed total triglyceride and fasting C-peptide to be significantly associated with coronary heart disease (Table 4). Glucose tolerance status (both diabetes and impaired glucose tolerance) remained significantly related to heart disease even after entry of C-peptide and triglyceride. Cigarette use measured by years smoked was also significantly associated with coronary heart disease. Alcohol intake by categories "moderate intake" and "heavy intake" entered the model together with the former showing a significant inverse association with coronary heart disease and the latter no association with heart disease. Diastolic blood pressure level also entered the model, but hypertension defined as blood pressure $>140 / 90$ did not. All other variables were non-significant and did not enter the model.

\section{Discussion}

There is an increased prevalence of coronary heart disease with both impaired glucose tolerance and Type 2 diabetes [1,2]. Nisei men known to have a high prevalence of both impaired glucose tolerance and Type 2 diabetes also have a significantly increased prevalence of coronary heart disease associated with glucose intolerance (both diabetes and impaired glucose tolerance). The finding that total triglyceride and fasting C-peptide were the only variables significantly associated with coronary heart disease after adjustment for glucose tolerance in a stepwise multiple logistic regression analysis agrees with another study in a separate immigrant Asian population in which elevation of both triglyceride and C-peptide were also associated with coronary heart disease [29].

Although obesity is often reported as being a risk factor for coronary heart disease, this has not been a consistent finding in men over 45-years-old [30]. Moreover, the association of obesity with coronary heart disease appears to be mediated by other risk factors [13]. Several studies have suggested that site specific body fat measurements may be a better predictor of CHD than overall obesity or adiposity $[13,31-33]$. In particular, measurements of upper body or central fat, such as subscapular skinfold thickness, the ratio of various skinfold thicknesses, and the waist to hip circumference ratio, have been reported as being significantly associated with coronary heart disease independent of body mass index. In two prospective studies, the waist to hip circumference ratio [31] and the subscapular skinfold thickness [33] were predictors of coronary heart disease even after adjustment for body mass index. One of these studies (Honolulu Heart Program) also examined Japanese-American men [33]. In the present cross-sectional study sample, subscapular skinfold thickness as well as forearm and biceps skinfold thickness and body mass index were associated with coronary heart disease, and of these, the subscapular skinfold thickness was most closely associated with heart disease; however, none of the skinfold measurements remained significant after adjustment for body mass index. This discrepancy with the Honolulu Heart Program may be related to the much smaller number of subjects in the present study (219 compared to 7692) or the differences in study design.

Another measure of central obesity is the intra-abdominal fat area determined by computed tomography, a variable previously shown to be associated with glucose intolerance $[32,34]$. In the present study, intra-abdominal fat area was the only adiposity and site-specific fat variable to remain significantly associated with coronary heart disease in two way analysis of variance with glucose intolerance as the other grouping variable, suggesting that the association of intra-abdominal fat area and heart disease was independent of glucose intolerance. Indeed, the relationship of the intra-abdominal fat area to glucose tolerance status was not significant in this two-way analysis. However, in the multiple logistic regression model, the association between intra-abdominal fat and coronary heart disease was no longer significant possibly due to the strong association of intra-abdominal fat with both fasting C-peptide and triglyceride. A recent study confirms the 
significant association of the intra-abdominal fat area determined by computed tomography with both insulin and triglyceride in a healthy population [32]. In another study intra-abdominal fat area determined by computed tomography was correlated to various plasma lipoprotein levels independent of body mass index [35].

The lipoprotein abnormalities associated with coronary heart disease in this population of Nisei men included elevated total and VLDL triglyceride, and decreased apoprotein $\mathrm{A}_{1}$, and $\mathrm{HDL}$ and $\mathrm{HDL}_{2}$ cholesterol levels. This lipoprotein profile is one commonly observed in Type 2 diabetes $[2,17]$. In Type 2 diabetes, the abnormal VLDL levels have been attributed to both increased production and decreased clearance of VLDL $[2,13,17]$. In populations with a high prevalence of glucose intolerance, triglyceride levels have been found to be elevated in those who develop coronary heart disease $[19,36]$. However, although hypertriglyceridaemia is often associated with coronary heart disease, whether hypertriglyceridaemia has an independent causal relationship with coronary heart disease has been questioned $[37,38]$. In several prospective studies in men, both without $[39,40]$ or with glucose intolerance [19], plasma triglyceride levels were found to be independently associated with heart disease, but HDL cholesterol levels were not assessed.

In our study sample, both total and VLDL triglyceride were associated with glucose intolerance and with coronary heart disease, independent of glucose intolerance. The association of hypertriglyceridaemia with glucose intolerance and coronary heart disease may reflect underlying abnormalities in metabolism of triglyceride-rich lipoproteins. In addition, LDL cholesterol levels were lower in men with coronary heart disease, although apoprotein B levels were not. There are several possible explanations for these findings. Although the mechanisms whereby elevated triglyceride may be atherogenic are unresolved, it is possible for the VLDL ultracentrifugation fraction to contain intermediate density remnants of the triglyceride-enriched lipoproteins; these have been reported as being elevated in Type 2 diabetes and are atherogenic $[1,2,14,41-43]$. Moreover, their plasma concentrations are significantly correlated with triglyceride levels. The significantly lower LDL cholesterol levels in the men with coronary heart disease could be the result of triglyceride-enriched or cholesterol-depleted LDL particles. Higher VLDL and intermediate density lipoprotein mass have been reported to be associated with small dense LDL particles [38]. An elevation of these potentially atherogenic remnant particles in the VLDL density range and decrease of cholesterol in the LDL density range might not affect the total apoprotein B measurements. Lower LDL levels have been observed in a group of newly diagnosed diabetic individuals with a high prevalence of coronary heart disease [44].

Numerous studies examining the general population have documented the association of coronary heart disease with low $\mathrm{HDL}$ and $\mathrm{HDL}_{2}$ cholesterol levels $[45,46]$. Studies examining populations of diabetic subjects have also demonstrated the association of low $\mathrm{HDL}$ and $\mathrm{HDL}_{2}$ cholesterol levels with coronary heart disease $[16,47,48]$. In the present study sample known to have a high pre- valence of Type 2 diabetes and impaired glucose tolerance, both reduced $\mathrm{HDL}$ and $\mathrm{HDL}_{2}$ cholesterol levels and reduced apoprotein $\mathrm{A}_{1}$ were associated with the presence of coronary heart disease. This association with coronary heart disease was not due to glucose intolerance since it persisted after adjusting for glucose intolerance. Low HDL cholesterol levels have been proposed to have a role in atherosclerosis by reducing cholesterol clearance from the arterial wall [49]. However, the HDL variable was no longer significant in the multiple logistic regression model possibly due to the significant inverse relationship of HDL cholesterol with triglyceride. It can be concluded from epidemiological studies that the relative contributions of reduced $\mathrm{HDL}$ and elevated triglyceride levels to development of coronary heart disease constitute an area of controversy $[38,39,50]$.

The association of coronary heart disease with elevations of both fasting insulin and $\mathrm{C}$-peptide levels adjusted for glucose tolerance status identifies hyperinsulinaemia as another risk factor for coronary heart disease independent of glucose tolerance status. Several prospective studies have also suggested this [3-6]. A recent study found normal glucose tolerant subjects with hyperinsulinaemia to have both elevated blood pressure and the lipid abnormalities often observed in glucose intolerant individuals, when compared to matched control subjects without hyperinsulinaemia [51].

Elevated fasting C-peptide levels in Nisei men with normal and impaired glucose tolerance have been shown to directly correlate with the deposition of intra-abdominal fat [11], and increased intra-abdominal fat has been reported to correlate with decreased insulin clearance [52], a manifestation of insulin resistance. This offers further support to the interpretation of elevated fasting levels of insulin and C-peptide as markers of insulin resistance. We hypothesize insulin resistance to be the primary abnormality in Nisei men and hyperinsulinaemia to be a compensatory response.

This insulin resistant condition is thought to be one feature of a syndrome characterized by the clustering of glucose intolerance, increased VLDL triglyceride, decreased HDL cholesterol, and increased risk of coronary heart disease and hypertension $[6,51,53-56]$. Several studies have demonstrated a significant positive correlation between the degree of insulin resistance as determined during a euglycaemic insulin clamp with total triglyceride and VLDL triglyceride, and significant negative correlation with HDL cholesterol, independent of adiposity $[10,57]$.

In conclusion, the findings from the present study are consistent with other epidemiological studies in the identification of risk factors for coronary heart disease. The important variables associated with coronary heart disease include glucose intolerance, increased intra-abdominal fat, elevated total and VLDL triglyceride, decreased HDL cholesterol, and hyperinsulinaemia. While all of these variables appear to be related to insulin resistance, with the multiple logistic regression analysis only total triglyceride and fasting $\mathrm{C}$-peptide, two variables linked physiologically to insulin resistance, in addition to glucose tolerance status retained significant associations with 
coronary heart disease. Thus, insulin resistance may be a common factor that underlies the development of all of these conditions associated with coronary heart disease and, although the precise mechanism for these relationships remains unresolved, may explain the association of glucose intolerance and atherosclerosis.

Acknowledgements. We thank Ms. J.Shofer for performing the multiple logistic regression analysis and for statistical advice, and the staff of the University of Washington Clinical Research Center for their assistance. We are indepted to the men of the King County Japanese-American community who participated in this study.

This research was supported by USPHS Grant (DK-31170) and by facilities and services of the Diabetes Endocrinology Research Center (DK-17047), the University of Washington Clinical Research Center (RR-37), and the Clinical Nutrition Research Unit (DK35816). Dr. Bergstrom was also supported by a Juvenile Diabetes Foundation International Postdoctoral Fellowship, the Nordstrom Research Fund in Metabolism and Food, and the Diabetes and Endocrine Training Grant (DK-07247).

\section{References}

1. Chait A, Bierman EL, Brunzell JD (1985) Diabetic macroangiopathy. In: Alberti KGMM, Krall LP (eds) The diabetes annual, Vol 1. Elsevier, New York, pp 323-348

2. Ruderman NB, Haudenschild C (1984) Diabetes as an atherogenic factor. Prog Cardiovasc Dis 26: 373-412

3. Pyorala K, Savolainen E, Kaukola S, Haapakoski J (1985) Plasma insulin as coronary heart disease risk factor: relationship to other risk factors and predictive value during $91 / 2$-year follow-up of the Helsinki Policeman Study Population. Acta Med Scand 701 [Suppl]: 38-52

4. Welborn TA, Wearne K (1979) Coronary heart disease incidence and cardiovascular mortality in Busselton with reference to glucose and insulin concentrations. Diab Care 2: 154-160

5. Eschwege E, Richard JL, Thibault N, Ducimetiere P, Warnet JM, Claude JR, Rosselin GE (1985) Coronary heart disease mortality in relation with diabetes, blood glucose and plasma insulin levels. The Paris prospective study, ten years later. Horm Metab Res 15 [Suppl]: 41-46

6. Modan M, Halkin H, Almong S, Lusky A, Eshkol A, Shefi M, Shitrit A, Fuchs Z (1985) Hyperinsulinemia: a link between hypertension, obesity, and glucose intolerance. J Clin Invest 75 : 809-817

7. Stout RW (1987) Insulin and atheroma-an update. Lancet I: 1077-1079

8. Garcia-Webb P, Bonser AM, Whiting D, Masarei JRL (1983) Insulin resistance - a risk factor for coronary heart disease? Scand J Clin Lab Invest 43: 677-685

9. Alberti KGMM, Davis SN, Monti L, Moller N, Piatti P, Heine R (1987) Methods for assessing insulin sensitivity in man. Biochem Soc Trans 15: 1027-1028

10. Garg A, Helderman JH, Koffler M, Ayuso R, Rosenstock J, Raskin P (1988) Relationship between lipoprotein levels and in vivo insulin action in normal young white men. Metabolism 37: 982-987

11. Bergstrom RW, Newell-Morris LL, Leonetti DL, Shuman WP, Wahl PW, Fujimoto WY (1990) Association of elevated fasting C-peptide level and increased intraabdominal fat distribution with development of NIDDM in Japanese-American men. Diabetes 39: 104-111

12. Malmquist J, Birgerstam G (1986) Assays of pancreatic B cell secretory products: utility in investigative and clinical diabetology. Scand J Clin Lab Invest 46: 705-713

13. Stern MP, Haffner SM (1986) Body fat distribution and hyperinsulinemia as risk factors for diabetes and cardiovascular disease. Arteriosclerosis 6: 123-130
14. Kissebah AH, Peiris AN (1989) Biology of regional body fat distribution: relationship to non-insulin-dependent diabetes mellitus. Diab Metab Rev 5: 83-109

15. Gordon T, Castelli WP, Hjortland MC, Kannel WB, Dawber TR (1977) Diabetes, blood lipids, and the role of obesity in coronary heart disease risk for women. Ann Intern Med 87:393-397

16. Reckless JPD, Betteridge DJ, Wu P, Payne B, Galton DJ (1978) High density and low density lipoproteins and prevalence of vascular disease in diabetes mellitus. Br Med J 1: 883-886

17. Howard BV (1987) Lipoprotein metabolism in diabetes mellitus. J Lipid Res 28: 613-628

18. Sicree RA, Zimmet PZ, King HOM, Coventry JS (1987) Plasma insulin response among Naurans: prediction of deterioration in glucose tolerance over 6 yr. Diabetes 36: 179-186

19. Fontbonne A, Eschwege E, Cambien F, Richard J-L, Ducimetiere, Thibult N, Warnet J-M, Claude J-R, Rosselin G-E (1989) Hypertriglyceridaemia as a risk factor of coronary heart disease in mortality in subjects with impaired glucose tolerance or diabetes. Results from the 11-year follow-up of the Paris prospective study. Diabetologia 32: 300-304

20. Robertson TL, Kato H, Rhoads GG, Kagan A, Marmot M, Syme SL, Gordon T, Worth RM, Belsky JL, Dock DS, Miyanishi M, Kawamoto S (1977) Epidemiologic studies of coronary heart disease and stroke in Japanese men living in Japan, Hawaii, and California: incidence of myocardial infarction and death from coronary heart disease. Am J Cardiol 39: 239-243

21. Fujimoto WY, Akanuma Y, Kanazawa Y, Mashiko S, Leonetti D, Wahl P (1989) Plasma insulin levels in Japanese and Japanese-American men with type 2 diabetes may be related to the occurrence of cardiovascular disease. Diab Res Clin Prac 6: 121-127

22. Fujimoto WY, Leonetti DL, Kinyoun JL, Newell-Morris L, Shuman WP, Stolov WC, Wahl PW (1987) Prevalence of diabetes mellitus and impaired glucose tolerance among second generation Japanese-American men. Diabetes 36: 721-729

23. Fujimoto WY, Leonetti DL, Kinyoun JC, Shuman WP, Stolov WC, Wahl PW (1987) Prevalence of complications among second-generation Japanese-American men with diabetes, impaired glucose tolerance, and normal glucose tolerance. Diabetes 36: 730-739

24. Poffenbarger RS, Wing AL, Hyde RT (1978) Physical activity as an index of heart attack risk in college alumni. Am J Epidemiol 108: 161-175

25. Rose GA, Blackburn $H$ (1968) Cardiovascular survey methods. World Health Organization, Geneva, pp 172-175

26. Rose GA, Blackburn H (1968) Cardiovascular survey methods. World Health Organization, Geneva, pp 137-141

27. Shuman WP, Newell-Morris LL, Leonetti DL, Wahl PW, Moceri VM, Moss AA, Fujimoto WY (1986) Abnormal body fat distribution detected by computed tomography in diabetic men. Invest Radiol 21: 483-487

28. Warnick GR (1986) Enzymatic methods for quantification of lipoproteins. Meth Enzymol 129: 101-123

29. Hughes L, Lahiri A, Raftery EB (1989) Coronary disease in Asians associated with high insulin and C-peptide concentration. Br Heart J 61: 445

30. Larsson B, Bjorntorp P, Tibblin G (1981) The health consequences of moderate obesity. Int J Obes 5: 97-116

31. Larsson B, Svardsudd K, Welin L, Wilhelmsen L, Bjorntorp P, Tibblin G (1984) Abdominal adipose tissue distribution, obesity and risk of cardiovascular disease and death: 13 year follow up of participants in the study of men born in 1913. BrMed J 288: 14011404

32. Peiris AN, Sothmann MS, Hoffmann RG, Hennes MI, Wilson CR, Gustafson AB, Kissebah AH (1989) Adiposity, fat distribution, and cardiovascular risk. Ann Intern Med 110: 867-872

33. Donahue RP, Abbott RD, Bloom E, Reed DM, Yano K (1987) Central obesity and coronary heart disease in men. Lancet I: $821-$ 824

34. Newell-Morris LL, Treder RP, Shuman WP, Fujimoto WY (1989) Fatness, fat distribution and glucose tolerance in second- 
generation Japanese-American (Nisei) men. Am J Clin Nutr 50: $9-18$

35. Despres J-P, Moorjani S, Ferland M, Tremblay A, Lupien PJ, Nadeau A, Pinault S, Theriault G, Bouchard C (1989) Adipose tissue distribution and plasma lipoprotein levels in obese women. Importance of intra-abdominal fat. Arteriosclerosis 9: 203-210

36. Janka HU (1985) Five-year incidence of major macrovascular complications in diabetes mellitus. Horm Metab Res 15 [Suppl]: $15-19$

37. Hulley SP, Rosenman RH, Bawol RD, Brand RJ (1980) Epidemiology as a guide to clinical decisions: the association between triglyceride and coronary heart disease. N Engl J Med 302: 1383-1389

38. Austin MA (1989) Plasma triglyceride as a risk factor for coronary heart disease. The epidemiologic evidence and beyond. Am J Epidemiol 129: 249-259

39. Bottiger L-E, Carlson LA (1980) Risk factors for ischaemic vascular death for men in the Stockholm prospective study. Atherosclerosis $36: 389-408$

40. Cambien F, Jacqueson A, Richard JL, Warnet JM, Ducimetiere P, Claude JR (1986) Is the level of serum triglyceride a significant predictor of coronary death in "normocholesterolemic" subjects? The Paris prospective study. Am J Epidemiol 124: 624632

41. Gabor J, Spain M, Kalant N (1980) Composition of serum verylow-density and high-density lipoproteins in diabetes. Clin Chem 26: $1261-1265$

42. Schwandt $\mathbf{P}$ (1985) Very low density lipoproteins in type II diabetes mellitus and risk of atherosclerosis. Horm Metab Res 15 [Suppl]: 80-83

43. Mahley RW (1982) Atherogenic hyperlipoproteinemia: the cellular and molecular biology of plasma lipoproteins altered by dietary fat and cholesterol. Med Clin N Am 66:375-402

44. Uusitupa M, Siitonen O, Voutilainen E, Aro A, Hersio K, Pyorala K, Penttila I, Ehnholm C (1986) Serum lipids and lipoproteins in newly diagnosed non-insulin-dependent (type II) diabetic patients, with special reference to factors influencing HDL-cholesterol and triglyceride levels. Diab Care 9: 17-22

45. Castelli WP, Doyle JT, Gordon T, Hames CG, Hjortland MC, Hulley SB, Kagan A, Zukel WJ (1977) HDL cholesterol and other lipids in coronary heart disease. The cooperative lipoprotein phenotyping study. Circulation 55: 767-772

46. Miller NE, Forde OH, Thelle DS, Mjos OD (1977) The Tromso heart study. High-density lipoprotein and coronary heart-disease: a prospective case control study. Lancet I: 965-967

47. Laakso M, Voutilainen E, Pyorala K, Sarlund H (1985) Association of low HDL and HDL2 cholesterol with coronary heart dis- ease in noninsulin-dependent diabetics. Arteriosclerosis 5: 653658

48. Welborn TA, Knuiman M, McCann V, Stanton K, Constable IJ (1984) Clinical macrovascular disease in Caucasoid diabetic subjects: logistic regression analysis of risk variables. Diabetologia 27: 568-573

49. Miller NE, LaVille A, Crook D (1985) Direct evidence that reverse cholesterol transport is mediated by high-density lipoprotein in rabbit. Nature 314: 109-111

50. Abbott RD, Carroll RJ (1984) Interpreting multiple logistic regression coefficients in prospective observational studies. Am J Epidemiol 119: 830-836

51. Zavaroni I, Bonora E, Pagliara M, Dall'Aglio E, Luchetti L, Buonanno G, Bonati PA, Bergonzani M, Gnudi L, Passeri M, Reaven $G$ (1989) Risk factors for coronary artery disease in healthy persons with hyperinsulinemia and normal glucose tolerance. New Engl J Med 320: 702-706

52. Peiris A, Meuller RA, Smith GA, Struve MF, Kissebah AH (1986) Splanchnic insulin metabolism in obesity. Influence of body fat distribution. J Clin Invest 78: 1648-1657

53. Wingard DL, Barrett-Connor E, Criqui MH, Suarez L (1983) Clustering of heart disease risk factors in diabetic compared to nondiabetic adults. Am J Epidemiol 117: 19-26

54. Zavaroni I, Dall'Aglio E, Bonora E, Alpi O, Passeri M, Reaven GM (1987) Evidence that multiple risk factors for coronary artery disease exist in persons with abnormal glucose tolerance. Am J Med 83: 609-612

55. Brunzell JD (1984) Obesity and coronary heart disease: a targeted approach. Arteriosclerosis 4: 180-182

56. Reaven GM (1988) Role of insulin resistance in human disease. Diabetes 37:595-607

57. Abbott WG, Lillioja S, Young AA, Zawadzki JK, Yki-Jarvinen H, Christin L, Howard B (1987) Relationships between plasma lipoprotein concentrations and insulin action in obese hyperinsulinemic population. Diabetes 36: 897--904 455-465

Received: 6 November 1989

and in revised form: 16 March 1990

Dr. W. Y. Fujimoto

Department of Medicine

Division of Metabolism

Endocrinology and Nutrition

RG-26, University of Washington

School of Medicine

Seattle, Washington 98195

USA 